\title{
Chapter 4 \\ Undone Science and Smart Cities: Civil Society Perspectives on Risk and Emerging Technologies
}

\author{
David J. Hess
}

Planning is currently underway for the development of a new urban infrastructure that will underlie the smart city. The envisioned future includes developing a smart grid, transforming buildings with the "internet of things," monitoring transportation remotely, commercializing air space for drones, and connecting vehicles to each other and the digital "cloud." The development of this digitized urban space is based on wireless communications that will increasingly connect and integrate the urban technological systems of electricity, transportation, and buildings. The smart city will require new research fields in engineering, computer science, and the social and behavioral sciences to guide technological innovation, regulatory policy, management strategies, and consumer interfaces that accompany the transition. Yet, this future smart city will be no different from past cities in at least one respect: it will be a contested space with different views about the design of the new technological systems and different knowledge claims that accompany controversies over design.

Because the world of connected and automated vehicles, digitized energy, and the "internet of things" has not yet arrived in full force, the contestation that will accompany its arrival has not yet crystallized, and the new urban space has not yet gained sustained attention from public-interest civil society organizations. One exception is the smart grid, which is already partially implemented in many parts of the world and has been accompanied by an emergent politics of knowledge and design. The smart grid is understood here as the application of digital technologies and computer software to a previously largely analog electricity system. Of special interest for the present discussion is the smart meter, which is the consumer interface of the smart grid. The smart meter is a digital electricity meter that enables the remote reading of a building's electricity consumption. In many countries, these digital meters have replaced the older analog meters. The new technology often makes it possible for the utility to engage in the direct management of internal

\author{
D. J. Hess $(\bowtie)$ \\ Department of Sociology, Vanderbilt University, Nashville, TN, USA \\ e-mail: david.j.hess@Vanderbilt.Edu
}


appliances such as air conditioning and heating systems. With the building owner's permission, the utility can send a signal to alter the setting on the heating and air conditioning system in order to control daily changes in the electricity load. The smart meter can also be used to provide time-of-use and real-time pricing to help manage peak load, to pinpoint power outages, to provide more effective responses, and to facilitate the adoption of distributed energy resources.

By studying how civil society organizations have reacted to the advent of the smart meter, one can begin to get a picture of the role of civil society in the broader transition to the future smart city. In this sense, the smart meter may be treated as a "harbinger technology" (that, is, a technology that serves as a forerunner of much greater levels of cyberphysical infrastructure) and used to foreshadow the as-yet unknown and emerging politics of the smart city. At the same time, the study of civil society and smart meters can also contribute to general social science knowledge about publics, science, and technology.

\section{Background Concepts}

In the study of knowledge, technology, and civil society, it is useful to begin with a distinction between social movements and civil society. The term civil society is understood here as a broad category of social organization and social relationship that is distinct from the family, the government, and the private sector. It is based on associational activity and can include clubs, religious groups, churches, charities, and political civil society; frequently, civil society organizations also have a special nonprofit tax status. In contrast, a social movement is a sustained mobilization of "challengers" (individuals and organizations) that are located in the subordinate positions of a social field (such as the electricity industry or the political field), that seek fundamental changes in the social field, and that encounter resistance to those changes from the "incumbents" located in the dominant positions of the field. Frequently, the leading organizations and individuals in a social movement are nongovernmental organizations that can be characterized as political civil society, but movements often include coalitions with elected and appointed political officials, scientists, religious groups, and segments of the private sector.

Researchers who study social movements have tended to build theory based on empirical research on mobilizations in the political field. Many such movements can be characterized as having a universalistic goal of achieving justice for disadvantaged groups based on race, ethnicity, class, gender, sexuality, age, and other dimensions of structural inequality. Many also have the universalistic goal of enhanced democratic governance, especially in conditions of dictatorship and corruption of governments. In contrast, the industrial transition movement can include these societal change goals, but it also has the goal of bringing about a fundamental change in an industry and/or an associated technological system (Hess, 2016). Adding this type of movement to the field of social movement studies reveals new 
areas of research for a general theory of social movements, most notably the relationship between movements and science and technology.

The industrial transition movement can be further subdivided into a set of four ideal types, of which actual movements frequently represent an amalgam (see Fig. 4.1). The central distinction is between aspirations that involve societal change and those focused more narrowly on technological systems and industrial change. If the primary goal is societal change, there are two main subtypes: enhancing democracy, such as transforming governance processes for the industrial system (e.g., more democratic regulatory processes) or developing new ownership patterns and organizational forms in the industry (e.g., municipalization, cooperatives, or community solar); and remediating situations of inequality, unfairness, and lack of access, such as mobilizations in favor of low-income energy assistance, price containment, and green job development. Likewise, if the goal is a sociotechnical transition, one can distinguish between the industrial opposition subtype-which has the goal of ending a technology, such as coal, or remediating its harmful effects, such as coal-ash spills - and the subtype of alternative industrial development, which has the goal of helping to bring to scale desirable innovations, such as renewable energy or energy efficiency.

The concept of an industrial transition movement, with these four subtypes, can be applied across a range of spatial scales and with a topical scope that suits the researcher's needs. For example, a researcher might examine opposition to naturalgas fracturing technologies at the continental scale or in a much smaller geographical region within a country. Likewise, the scope may include a range of subtypes of industrial transition movements in a demarcated spatial area. For example, a study of New York State electricity politics and policy since 2000 compared four mobilizations that mapped roughly onto the four subtypes to show how the mobilizations are networked through distinct coalitions of civil society and other organizations that exist in silos with relatively low overlap and communication among them (Hess, 2018). The project also showed a trend toward integration, and with the

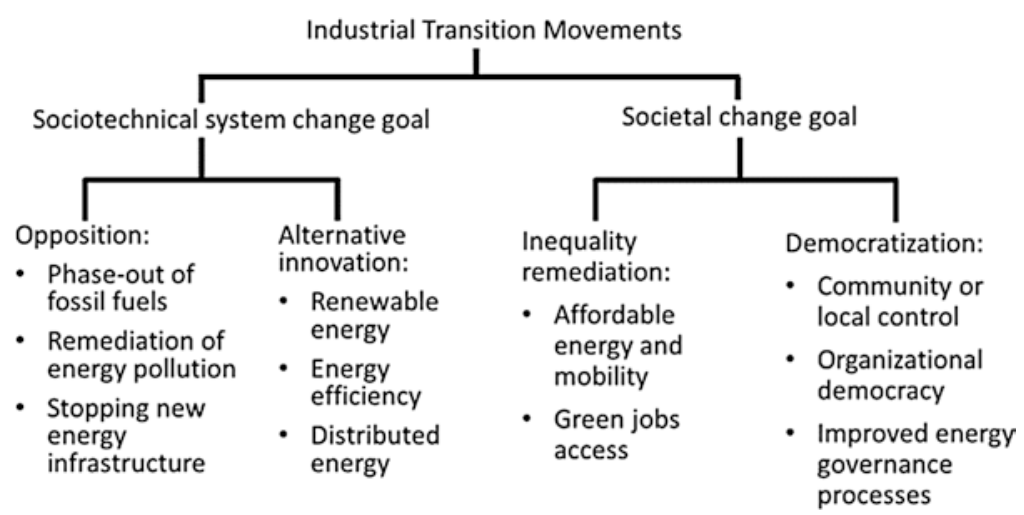

Fig. 4.1 Types of industrial transition movements (energy). Source: Design by author 
integration, the development of new organizations and frames, especially the broad frame of energy democracy.

This study will examine the emergence of the industrial transition movement associated with smart meter development in the US. As a constituent element of the smart grid, the smart meter has received attention because it represents the interface between the increasingly digitized electricity system and the customer-citizen. To a large extent private-sector actors developed the technology with little democratic deliberation and participation in its design and implementation. Members of the utility and the information-technology industries have assumed that the technology is beneficial because it will increase energy efficiency, reduce costs to the utilities and potentially to consumers, improve resilience in the event of power outages, and enable the integration of distributed energy resources such as rooftop solar. Yet, the implementation of the technological change raises a wide range of questions that are likely to become emblematic of challenges that will occur with the broader transition to smart cities.

The analysis that follows will focus on civil society, smart meters, and mobilizations in the United States and especially in California, where the mobilizations were the most intense and widespread. Public mobilizations and participation in smartmeter policy will be approached through the lens of industrial transition movements. Using this lens, one can discern all four subtypes:

1. Anti-smart-meter networks have emerged in some countries, and their members frequently criticize the lack of democratic process in the decision-making that led to the adoption of smart meters. These criticisms come from both the political left and right (Hess, 2014). In North America, smart-meter opponents sometimes link their action to the democratic goal of community or public control over energy generation, a goal that has appeared throughout the history of the electricity industry and that currently appears in movements to municipalize utilities or to shift to a form of local control known as community choice (Hess, 2019).

2. Members of anti-smart-meter networks have also expressed concern about the equity dimension, based largely on the unequal distribution of expenses that emerges with time-of-use pricing (Hess, 2014). The digital technology of smart meters can enable options for consumers to save on energy costs if appliances such as clothes dryers are used during off-peak hours. But such advantages are more readily available to households with time flexibility and with advanced technologies, and the technological change consequently becomes associated with an affordability and price-equity problem. Another example of an affordability problem occurs when regulators or utilities have allowed opt-out provisions to wireless smart meters, but they have charged prohibitively high monthly fees for consumers who wish to exercise the option (e.g., The Utility Reform Network, 2012).

3. Members of smart-meter mobilizations also show concern about technical and design issues such as the possible health effects of smart meters and about privacy and security. The former concern is rooted in health risks claimed to be 
associated with low-level microwave radiation, and the latter with the potential to know what people are doing inside the home because of the unique signature of appliances and even movies.

4. The mobilizations can involve support for a wide range of technological innovations, such as support for design innovation that ensures privacy for the new technologies or support for an emerging industry that has produced a wide range of products and services that provide shielding from non-ionizing electromagnetic radiation.

This study will focus on the third and fourth types of industrial transition movement subtypes, that is, efforts to address the sociotechnical change goals of health and privacy-security, both in the oppositional and pro-alternative variants. In the US for each of these issues, there is a moderately developed network of civil society organizations that can provide a basis for the exploration of knowledge, technology, civil society, and undone science.

In addition to bringing to the study of knowledge and civil society the lens of industrial transition movements, this study also draws attention to the diversity of goals among civil society organizations. Three basic types of organizations will be discussed here. First, anti-smart meter groups tend to be informal, grassroots organizations that emerge during the installation period. There is not enough research yet to understand the conditions for their mobilization and demobilization, but it is possible that achieving an opt-out rule at an affordable cost may be the condition that leads the groups to go into abeyance. These groups raise a wide range of concerns with respect to smart meters, including democracy and equity goals, but frequently in North America the groups focus especially on risks to health, privacy, and security. Second, privacy organizations have a broad range of concerns about privacy and are generally more formal and well-established organizations. They may be considered as a subset of the broader movement of consumer organizations, and they occasionally become active in the field of smart-meter politics. Third, EMF risk organizations are sometimes formal nonprofit organizations, but in some cases, they are only information-providing web sites that are linked to EMF remediation businesses. Thus, these organizations can represent a combination of civil society and entrepreneurial business organizations. The three sections that follow will discuss each of these three types of civil society and their responses to smart meters.

With respect to the question of knowledge and ignorance, these three types of civil society actors draw attention to the need for different types of knowledge. Some of the knowledge is future knowledge that utilities and other industrial organizations accept as necessary, such as the computer science and engineering knowledge needed to provide assurances of privacy that are necessary for consumer acceptance. However, some of the knowledge is also what I and others have termed undone science. The concept of undone science is situated in the broader field of research on knowledge and ignorance as one of the many forms of ignorance (Gross \& McGoey, 2015; Hess, 2020). Among the different types of nonknowledge, undone science has two main elements. First, it is a specified absence or low quantity of scientific research; in other words, it is a possible future knowledge that can be 
identified as needed or wanted. Many actors in the state, industry, science, and civil society frequently identify future research agendas of desired but as yet incomplete knowledge. However, undone science is more specific than simply a formulation of desired future knowledge. The second aspect of undone science is that it is a situated knowledge that is identified by reformers who claim to speak for a broad public interest, such as members of public-interest civil society organizations, who think that the public would benefit from knowing more about a topic. In the context of emerging technologies, undone science often refers to research on health, environmental, privacy, safety, or other kinds of risk. Industrial actors and allied groups that are supporting the new technologies have rejected research that documents risk, safety, or other public interest concerns as unwanted, and, in some cases, they have worked to suppress or defund the research.

When this situation occurs, some researchers may still take up the challenge, but they often do so in marginalized settings such as unfunded work by independent scientists. Thus, undone science refers to a specification of what is unknown but potentially knowable and that if known, might help advocates of the public interest to defend better regulation, innovation, and public protections. It is knowledge that can be positioned to have potential effects in the political field.

\section{Grassroots Anti-Smart-Meter Mobilizations}

Grassroots anti-smart-meter networks emerged throughout North America, but the most concentrated mobilizations were on the West Coast from California to British Columbia (Hess, 2014; Hess \& Coley, 2014). These networks generally were not comprised of formal, nonprofit organizations, but they sometimes included participation from formal organizations, including the EMF organizations to be described below. The reasons given for opposition varied substantially. Analyses of testimony and media reports indicate that health concerns from wireless microwave transmission were paramount (Hess, 2014; Hess \& Coley, 2014). The mobilizations tended to attract a wide range of political perspectives, from conservatives who were concerned about "big brother" to progressives concerned about democracy, process, and precautionary politics.

The grassroots mobilizations resulted in many local government resolutions and ordinances as well as extensive public testimony and some protest. Although the anti-smart meter advocates were unable to stop the smart-meter deployment or to gain a design shift to wired meters, in 2012 the California Public Utilities Commission approved an opt-out program that allowed customers to retain an ana$\log$ meter for a fee, and other states and provinces offered similar concessions. In the case of California, anti-smart-meter advocates supported the measure in general terms, but some program issues remained controversial. An investor-owned utility argued that in addition to the option to switch back to an analog system, customers could also opt-out by accepting a modified smart meter with the radio turned off. The utility maintained that the radiofrequency emissions from the "radio off" smart 
meters were well within the federal government's safety standard and that leaving the already installed smart meters would allow greater flexibility for future customers. However, opponents as well as a number of local governments continued to be concerned about the health effects of the meters even with the radiofrequency turned off, and they fought for the right to remove the meters rather than rely on modification of the already installed smart meters (California Public Utilities Commission, 2011). The anti-smart-meter groups also advocated against opt-out fees because the charges for customers far outweighed the costs for utilities to reinstall the analog meters. In 2014, the Public Utilities Commission agreed to cap the monthly optout fees.

The grassroots anti-smart-meter networks did not generate new scientific knowledge. Some proponents created citizen science in the form of YouTube videos that measured radiofrequency emissions from smart meters and provided testimonials from people who claimed to have experienced health effects. The main relationship with scientific knowledge was the circulation of knowledge, that is, explaining to the public and to local governments why a moratorium was needed while more safety research was conducted or why an opt-out policy should be required in the absence of a moratorium. The arguments included references to scientific research on potential health effects of living in proximity to constant wireless emissions from smart meters.

\section{Privacy Organizations}

An important reason why the advent of the smart meter has raised concerns from consumers and public-interest civil society organizations is that each appliance has a unique electronic signature. Thus, it is possible to know when people are home and what they are doing there, a prospect that conjures up images of Orwell's 1984 (1949). As with other internet-based technologies, privacy standards are vital to guide what kind of information will be collected, the degree of granularity of the information, how the information will be used, when it will be deleted, and who has access to it. Furthermore, there are closely connected security issues based on the risk of breaches of private information or the possibility of assembling information into detailed pictures of each person. Criminals could use records to determine when people are at home or away from home, and they could potentially also cause fires by hacking into heating units. Thus, privacy and security issues are closely interwoven.

Whereas governments and industry tend to dismiss health concerns, they are much more willing to entertain the need to develop good privacy and security standards. Industry recognizes that without public confidence, resistance will rapidly mount and lead to the discrediting of smart meters and the "internet of things." In the United States, recognition of the importance of the problem has grown with each new major privacy breach, and the European Union's General Data Protection Regulation also affected privacy practices on the North American continent. Thus, 
the relationship between civil society organizations that advocate for privacy and industrial incumbents such as the utilities is much less oppositional than for the goal of opt-outs or moratoria. Nevertheless, in the US there is considerable public awareness that government legislators and regulators are captured by industrial interests. In response, privacy advocacy organizations have played a public-interest role by pressuring the federal and state governments to adopt better privacy standards and implementation.

As for many issues involving energy and new technologies, California has been a leader in the United States. The state government's constitution includes a privacy provision, and a state law (Senate Bill 17 of 2009) authorized the California Public Utilities Commission to enact privacy provisions. Two civil society organizations, the Electronic Privacy Frontier Foundation and the Center for Democracy and Technology, provided comments in the regulatory process for privacy and smart meters in the state (Lynch \& Tien, 2010). The organizations carefully opened their comments by discussing the benefits of smart meters; hence, the position of these civil society organizations was not in opposition to smart-meter installations.

In contrast with the grassroots anti-smart-meter mobilizations, the privacy organizations did not argue that smart-meter deployment should be halted or that affordable opt-out provisions should be immediately implemented. Rather, they asserted that the California Public Utilities Commission should adopt regulatory policy that follows the general fair information practices principles (Lynch \& Tien, 2010). These principles exist in various versions, and the organizations' testimony included the following: transparency of data management practices, individual participation with consent, purpose specification for data use, data minimization, use limitation, data quality and integrity (accurate, timely, complete), data security, and accountability and auditing. (These principles also appear in the European Union's General Data Protection Regulation.) The organizations also advocated for a prohibition on nondisclosed use by third parties and for a requirement of data destruction when the specified use is no longer operational.

In 2011, the privacy organizations claimed that the California Public Utilities Commission had accepted their recommendations (Jeschke, 2011). Senate Bill 1476, which legislators enacted that year, prohibited utilities from sharing, disclosing, selling, or otherwise making accessible to third parties a customer's data, which includes information about electrical and gas consumption, without the consent of the customer. The measure also required utilities to use "reasonable security procedures and practices" to protect these data (Senate Bill 1476 of 2010). In 2014, the state government approved Assembly Bill 1274, which expanded the earlier smart meter privacy law by putting the same restrictions on businesses that work with smart meter data, such as internet service providers and financial institutions.

The approval of privacy principles and regulations is only part of the story; with the advent of these regulations, there must be effective implementation. The effectiveness of privacy implementation depends in part on the willingness of utilities to follow through with the legislators' and regulators' intent, but it also requires new knowledges and technologies to ensure privacy. Privacy technology assurances need to be developed. For example, how frequently should a customer's electricity 
consumption be sampled? Does a less frequent rate of sampling, such as once per day, ensure privacy, or is it still possible to figure out home activities? Should customer data be aggregated, and if so, what rules of aggregation should be followed? The utilities can bring together readings from multiple smart meters to reach a total energy reading but without obtaining any data on a specific household's energy consumption (Cavoukian \& Polonetsky, 2013). Researchers are still developing privacy aggregation protocols for smart meters that are tolerant of communication failures or smart-meter malfunctioning in order to avoid privacy breaches (e.g., Hoepman, 2017; Won, Ma, Yau, \& Rao, 2016). However, aggregation may also make it difficult to use real-time pricing programs, and other ways of protecting privacy may be preferable. These questions and problems help to motivate the development of a new knowledge associated with the management of privacy for the smart grid. In turn, this area of privacy research is a subfield of the emerging field of "privacy engineering," for which graduate education is now becoming available.

In summary, the mobilization of privacy organizations has generally operated within the framework of acceptance of the technological transition. Civil society organizations have articulated privacy principles and privacy guidance, and the push for good privacy practices has helped to stimulate the development of new knowledges and technologies (even a new research field) in privacy engineering. Many questions remain unanswered, and many problems remain unsolved, but the development of privacy science and technology for the smart grid is a developing scientific research field rather than undone science. The utilities and related companies recognize the need to implement the technology in order to ensure the overall public acceptance of the technological transition, and the implementation of the General Data Protection Regulation in Europe in 2018 is having significant spillover effects on North American policies and practices. In other words, resources are already forthcoming to develop the science and technology needed to meet policy goals and guidelines for privacy standards, and the field of privacy research is untroubled by industry-based attacks on its credibility. Such is not the case for the third type of civil society mobilization.

\section{EMF Risk Organizations}

EMF risk (or safety) organizations include informational web sites run by individuals, small businesses, and formal nonprofit organizations. They have existed for decades, and they have been involved in a wide range of public controversies involving risk from non-ionizing EMF. This category of EMF includes high-voltage power lines and electricity transformer sites near homes and schools, faulty wiring and dirty electricity inside buildings, the use of radar on military bases near civilian residences, the safety of radar for military and police workers, microwave ovens, computers, cell phone towers (mobile phone masts), wi-fi, cell phones, and cordless phones. In North America, the primary intersection of the EMF risk organizations 
with the politics of smart meters involves the potential health risks from exposure to wireless transmission.

An informal survey by a smart-meter organization indicated that common complaints include sleep disturbances, stress and anxiety, headaches, and tinnitus (Halteman, 2011). The peer-reviewed research tends to come from the related field of research on the effects of microwave radiation associated with cell phones and towers (mobile phones and masts). In other words, there is very little direct research on the health effects associated with wireless smart meters. However, the research on wi-fi and cellular phones is relevant because it involves a similar frequency of EMF radiation to the one used for wireless smart-meter transmissions.

Because the power density of the EMF radiation declines rapidly with distance, a person's exposure is affected by the location of the meter installation on the outside wall of the building, the size of the building, and how much time the person spends in the room near the meter. A meter bank in an apartment complex where the inside space is a bedroom or office would expose occupants to much higher EMF emissions than a single meter located on the outside of a garage and away from sleeping areas. (High levels of exposure may also apply to people who sleep with their wi-fi routers next to their beds and cell phones under their pillows).

Researchers who study health effects of EMF radiation have recommended precautionary standards, and some areas of the world have enacted standards close to these recommendations. Whereas the US standard is set at a non-precautionary level of $10,000 \mu \mathrm{W} / \mathrm{cm}^{2}$, which is based on thermal or tissue-heating effects, other areas of the world recognize standards based on nonthermal biological effects. The Council of Europe (2011) has recommended a maximum indoor exposure level of $.6 \mathrm{~V} / \mathrm{m}\left(.1 \mu \mathrm{W} / \mathrm{cm}^{2}\right)$ and a medium-term goal of $.2 \mathrm{~V} / \mathrm{m}\left(.01 \mu \mathrm{W} / \mathrm{cm}^{2}\right)$. A group of experts in Norway recommended a whole-body exposure limit of $.17 \mu \mathrm{W} / \mathrm{cm}^{2}$, with a potential precautionary limit of $.017 \mu \mathrm{W} / \mathrm{cm}^{2}$ (Fragopoulou et al., 2010). In Germany, the Institut für Baubiologie + Ökologie (2008; Institute for Building Biology and Ecology) designated $.001 \mu \mathrm{W} / \mathrm{cm}^{2}$ as the boundary between slight and severe concern. The BioInitiative Report (BioInitiative Working Group, Sage, \& Carpenter, 2012), which was written by an international network of EMF health experts, recommended a precautionary indoor exposure limit equivalent to .0003$.0006 \mu \mathrm{W} / \mathrm{cm}^{2}$.

Although the standards are helpful guidelines, they can be confusing in practice. For example, using the relatively accurate Acoustimeter, a smart meter installed on the outside wall of the garage of the house of the author generates an average inside power density of $.0001-.0005 \mu \mathrm{W} / \mathrm{cm}^{2}$ at three meters with one layer of aluminum foil shielding on the inside wall, and it has spikes or peak frequencies of .01-.06 $\mu \mathrm{W} / \mathrm{cm}^{2}$. The evaluation of safety or risk depends partly on which standard is used, whether one uses average or peak power densities, and how far one is from the smart meter. Moreover, the health effects literature, which includes hundreds of studies, is not always calibrated to the power density units used in measurement devices.

Nevertheless, by the twenty-first century, radiofrequency meters have become widely available and marketed through the network of EMF safety and remediation companies. In addition, an industry of EMF consultants and businesses, with 
certification and training, has emerged to help building owners to evaluate and remediate high emissions. Thus, it is possible to have a building evaluated and to measure exposure, as well as to remediate exposure just as is done for radon risk. But doing so requires some knowledge and financial resources, a problem that leads to intersections with the equity goal that sometimes emerges in the EMF health-risk organizations.

Although the level of risk associated with microwave transmissions remains unknown, every year the public health and subclinical peer-reviewed research continues to document more health effects. This situation is an example of undone science, whereby the incumbent actors of an industrial regime view additional research as potentially threatening to the current configuration of the technological system, a view that is backed by systematic underfunding and a history of some attacks on scientists who have documented risk. In the case of research on the health effects of wireless technologies, there is little government-sponsored research in the US, and scientists who engage in research in this field risk their careers. Journalists and scientists have documented the systematic reduction of funding from the government to independent scientists that began to be evident by the early 1980s, and they have also documented the campaigns by the military and industry to discredit or bury independent research that demonstrates health effects (e.g., Becker \& Selden, 1985; Brodeur, 1977; Marino, 2010). Rather than seek answers to these questions and develop low-emissions technologies and shielding, industry members have instead sought to reassure consumers about the safety of EMF radiation and to support a view of the research field on health effects of EMF radiation as in a permanent state of inconclusive knowledge. This approach to the research field is similar to the one that industry members have adopted toward research on climate change, some chemicals, and tobacco, where the goal is to prevent regulatory intervention by arguing that the science is unsettled and that there is no basis for the regulation based on an industry definition of "sound science" (Oreskes \& Conway, 2010; Rampton \& Stauber, 2001).

The other side of undone science is the generation of incumbent science. A systematic review of research has documented how industry-funded science tends to produce negative findings about health risk from EMF at a significantly higher rate than independent science (Huss, Egger, Hug, Huwiler-Müntener, \& Röösli, 2007). Incorrect information about health risks then circulates through public relations campaigns. An example of the utilities' approach to safety concerns appears on the web site of the Smart Energy Consumer Collaborative, an industry group that educates consumers about the benefits of smart meters. With respect to health concerns, the website had the following quote: "It would take 375 years of direct contact with a smart meter to equal the same amount of radio frequency exposure from a daily, 15-minute cell phone call over the course of one year" (Smart Energy Consumer Collaborative, 2020). This quotation appears on other websites used to reduce the concerns of customers about health effects. The authority for the quotation is a study by the California Council on Science and Technology (2011), which various independent EMF researchers have criticized for accuracy (Carpenter, 2011; Hirsch, 2011; Maret, 2011). Civil society organizations generally do not enter directly into 
the scientific controversy, which is best left to researchers, but EMF risk organizations such as the Center for Electrosmog Prevention (2011a) have publicized the flaws of the study. Moreover, smart-meter groups have raised additional questions about the credibility of other experts employed by industry (Burke, 2015).

In addition to challenging industry assertions that there is no scientific basis for health risks that customers and smart-meter groups raise, EMF risk organizations also participate in government regulatory proceedings by providing knowledge and information. For example, the Center for Electrosmog Prevention participated in the California Public Utilities Commission rule-making, and the EMF Policy Institute participated in federal rule-making procedures. The organizations defended opt-out provisions and pointed to the need to provide protection for persons with health conditions and disabilities that may require special consideration with respect to exposure to EMF fields. Without invoking the disputed category of electrosensitives, these organizations cited studies that medical implants may malfunction with exposure to wireless smart-meter emissions (Singer, n.d.). They argue that current safety policies fail to protect these groups of people and that policies such as opt-out fees violate the Americans with Disabilities Act, a connection that links the sociotechnical goal of emissions reduction with the equity goal of remediation of rights. The Center for Electrosmog Prevention (2011b) stated that to charge these vulnerable populations for opt-out rights is "similar to denying a person in a wheelchair any access to services, with the exception of a "for-fee ramp."

As in the case of privacy-related mobilization, health concerns can also be the basis for the development of new technologies. In this case, the most obvious alternative technology is wired technology that would connect the meter to the utility through fiber-optic cables. This feasible technological substitution makes it possible to avoid the entire question of the health effects of wireless transmission, but it would require cooperation with the cable or land-line industries, and it could mean cost increases for the utilities. (Wired technology also does not eliminate health-risk concerns, which have occurred in some parts of Europe even for wired technology). In the absence of wired technology, there is an industry of companies that offer a wide range of products designed to reduce exposure: fabrics, clothing, and paints that reduce EMF exposure; shielding devices for smart meters, cell phones, routers, automobile cabins, and computers; books and videos; and a wide range of devices that can measure exposure.

Some countries and subnational regions have wired systems, and some countries have also restricted wi-fi for the most vulnerable segments of the population. For example, in France wi-fi has been banned in nursery schools and minimized in elementary schools. But the main way of achieving the goal of reduced exposure to microwave radiation is to develop and use wireless technology at levels of power density below which health effects have not been demonstrated. Numerous technical design solutions could be developed to reduce emissions, just as has been done for emissions from power plants and vehicles, but unlike privacy research, this topic is largely one of undone science and industrial non-innovation.

On the whole, EMF risk organizations face an uphill battle. People are unlikely to give up the convenience of wireless technology, especially for cell phones, and 
the primary way to resolve public health concerns is likely going to be through the design of a next generation of technologies that has lower microwave emissions. At this point, it is not possible to say with assurance what the acceptable minimum level of exposure to wireless microwave radiation should be because researchers have not yet found a threshold minimum dose. Whereas this question is one for the natural and health sciences, a social science perspective can point to another type of conclusion: there is a policy collision looming ahead. On the one hand, publichealth researchers continue to generate knowledge about health risks at low exposures, and the lowest observed effect level at which health effects are evident continues to decline. On the other hand, the wireless industry continues to push new technologies in the home, the workplace, the transportation system, and even on lamp posts, which is generating more, not less, cumulative exposure. It is possible that future research and policy will establish a minimum threshold level below which biological effects are not detected, and it is possible that this level will still allow a next generation of wireless technology to function adequately. But no one will know if the research is not being done.

One example of the potential collision course ahead is the fate of California's Senate Bill 649 of 2017. Had it been approved, the bill would have required local governments to lease out public property, such as streetlights and traffic signal poles, to the wireless industry for the installation of "small cell" telecommunications facilities. The bill would have also capped the fees local governments can charge these companies, and it would have restricted cities' ability to gather public input and negotiate leases. Proponents of the bill argued that the measure would expand the state's connectivity, bring it closer towards the $5 \mathrm{GHz}$ future of telecommunication, and boost the economy. Unsurprisingly, local governments opposed the bill because it would have eliminated their discretion over how to use public property. Activists and scientists also argued that the radiation and electromagnetic frequencies emitted by cellular towers in public buildings and utility poles would create a public health risk. Governor Edmund "Jerry" Brown vetoed the bill in October 2017.

\section{Conclusions}

Several general implications emerge from this review of different aspects of one industrial transition movement in one country. First, with respect to the general social science problem of understanding the connections between civil society and the politics of knowledge, this analysis points to the value of tracking differences across civil society organizations and coalitions even where they may have mostly consistent objectives (Hess, 2018). Grassroots networks were focused mostly on gaining moratoria and opt-out provisions; electronic privacy organizations drew attention to the implementation of good privacy principles; and EMF safety organizations underlined health-related risks, potential violations of disability law, and the value of remediation technologies. 
Second, although some connections with the equity goal were flagged, this study has focused more on the sociotechnical side of industrial transition movements than on the societal change goals that sometimes emerge in the context of the smart grid. The advantage of a broad typology is that it enables questions about what other types of politics might have been left out of the analysis. Examples of societal transition goals that sometimes emerge in the context of smart grid politics include democracy goals (e.g., improved democratic participation in rule-making and standards and the broader question of public ownership of electricity systems) and equity goals (e.g., the cost of opt outs and the effects of wireless exposure on persons with chronic health conditions and pacemakers). But even within the category of sociotechnical change goals, this study shows how goals often overlap in practice. For example, oppositional goals—such as a moratorium or opt-out policywill tend to coincide with generative goals-such as support for the remediation industry. The mobilizations help to create the conditions that favor the generation of new types of knowledges and technologies, such as privacy engineering and EMF remediation. Older technologies, such as wired transmission systems, receive new valuation from a safety perspective.

Third, these movements draw attention to the politics of research priorities and agendas. Although mobilizations of civil society organizations can help to motivate the generation of new research fields and associated technological innovation, the position of these research fields with respect to the incumbents of the industrial fields can vary dramatically. The utilities seem willing to swallow the pill of privacy restrictions in order to reap the gains of time-of-use pricing, grid resilience, load stability, and reduced labor costs. But the prospect of a return to analog meters is a much more fundamental threat to the future electricity grid, and the shift to a wired system may entail competitive risks from the telecommunications industry. Moreover, although wired systems are feasible for smart meters and for computer connections in buildings, they pose an existential threat to the future world of connected transportation and mobile connections. Thus, one type of knowledge- privacy engineering - is merely part of the terrain of a complex digital world in which almost anything about individuals is potentially knowable, whereas the other type of knowledge-health risks from wireless communications-poses a potentially deeper set of challenges. One type of knowledge is merely a future and emergent research field, whereas the other suffers from loss of government funding, industryfunded counter studies, and other mechanisms that create a situation of undone science and non-innovation. Social movements can play a vital role in the democratic politics of technology by helping to identify undone science, to mobilize resources to help get the science done, and to open up policy decisions to democratic political processes that include industry perspectives but are also insulated from industry pressure.

Acknowledgements This project was partially supported by the US National Science Foundation, OISE-1743772, Partnerships for International Science and Engineering (PIRE) Program: "Science of Design for Societal-Scale Cyber-Physical Systems." Any opinions, findings, conclusions, or recommendations expressed here do not necessarily reflect the views of the National Science Foundation. I thank Magdalena Sudibjo for research assistance on portions of the paper. 


\section{References}

Becker, R. O., \& Selden, G. (1985). The body electric: Electromagnetism and the foundation of life. New York: William Morrow and Company.

BioInitiative Working Group, Sage, C., \& Carpenter, D. O. (Eds.). (2012). The BioInitiative report: A rationale for a biologically-based public exposure standard for electromagnetic fields (ELF and $R F$ ). Retrieved from http://www.bioinitiative.org

Brodeur, P. (1977). The zapping of America: Microwaves, their deadly risk, and the coverup. New York: W. W. Norton \& Company.

Burke, P. (2015). Ethics complaint. Retrieved from www.stopsmartmetersbc.com/wp-content/ uploads/2015/10/hirsch-sept-2015-finaL-2.doc

California Council on Science and Technology. (2011). Health impacts of radio frequency exposure from smart meters: April 2011-Final report. Retrieved from https://ccst.us/ publications/2011/2011smart-final.pdf

California Public Utilities Commission. (2011). Decision modifying Pacific Gas and Electric Company's smartmeter program to include an opt-out option. Retrieved from http://docs.cpuc. ca.gov/PUBLISHED/AGENDA_DECISION/158309.htm

Carpenter, D. O. (2011). Sage reports: Expert letters to CCST: David O. Carpenter, M. D. Retrieved from http://sagereports.com/smart-meter-rf/?p=297

Cavoukian, A., \& Polonetsky, J. (2013). Privacy by design and third-party access to customer energy usage data. Retrieved from https://www.ipc.on.ca/wp-content/uploads/Resources/pbdthirdparty-CEUD.pdf

Center for Electrosmog Prevention. (2011a). Smart meters radiation exposure up to 160 times more than cell phones (Hirsch). Retrieved from http://www.electrosmogprevention.org/ public-health-alert/smart-meters-radiation-exposure-up-to-160-times-more-than-cellphones-hirsch/

Center for Electrosmog Prevention. (2011b). Opening brief of Center for Electrosmog Prevention on smart meter opt out restrictions imposed by Americans with Disabilities Act or California Public Utilities Code 453(B). Retrieved from http://docs.cpuc.ca.gov/publisheddocs/efile/ brief/170230.pdf

Council of Europe. (2011). The potential dangers of electromagnetic fields and their effects on the environment. Resolution 1815. Retrieved from http://assembly.coe.int/nw/xml/XRef/XrefXML2HTML-en.asp?fileid=17994\&

Fragopoulou, A., Grigoriev, Y., Johansson, O., Margaritis, L. H., Morgan, L., Richter, E., \& Sage, C. (2010). Scientific panel on electromagnetic field health risks: Consensus points, recommendations, and rationales. Reviews on Environmental Health, 25, 307-317. https://doi. org/10.1515/REVEH.2010.25.4.307

Gross, M., \& McGoey, L. (2015). Routledge international handbook of ignorance studies. Abingdon: Routledge.

Halteman, E. (2011). Wireless utilities meter safety impacts survey: Final results summary September 13, 2011. Retrieved from http://emfsafetynetwork.org/wp-content/uploads/2011/09/ Wireless-Utility-Meter-Safety-Impacts-Survey-Results-Final.pdf

Hess, D. J. (2014). Smart meters and public acceptance: Comparative analysis and governance implications. Health, Risk \& Society, 16, 243-258. https://doi.org/10.1080/1369857 5.2014.911821

Hess, D. J. (2016). Undone science: Social movements, mobilized publics, and industrial transitions. Cambridge, MA: MIT Press.

Hess, D. J. (2018). Energy democracy and social movements: A multi-coalition perspective on the politics of sustainability transitions. Energy Research \& Social Science, 40, 177-189. https:// doi.org/10.1016/j.erss.2018.01.003

Hess, D. J. (2019). Coalitions, framing, and the politics of energy transitions: Local democracy and community choice in California. Energy Research \& Social Science, 50, 38-50. https://doi. org/10.1016/j.erss.2018.11.013 
Hess, D. J. (2020). The sociology of ignorance and post-truth politics. Sociological Forum, 35, 241-249. https://doi.org/10.1111/socf.12577

Hess, D. J., \& Coley, J. S. (2014). Wireless smart meters and public acceptance: The environment, limited choices, and precautionary politics. Public Understanding of Science, 23, 688-702. https://doi.org/10.1177/0963662512464936

Hirsch, D. (2011). Comments on the draft report by the California Council on Science and Technology "Health impacts of radio frequency from smart meters." Retrieved from http:// www.ccst.us/projects/smart2/documents/letter8hirsch.pdf

Hoepman, J.-H. (2017). Privacy friendly aggregation of smart meter readings, even when meters crash. In R. Bilof (Ed.), CPSR-SG'17: Proceedings of the 2nd Workshop on Cyber-Physical Security and Resilience in Smart Grids (pp. 3-7). New York: Association for Computing Machinery. https://doi.org/10.1145/3055386.3055389

Huss, A., Egger, M., Hug, K., Huwiler-Müntener, K., \& Röösli, M. (2007). Source of funding and results of studies of health effects of mobile phone use: Systematic review of experimental studies. Environmental Health Perspectives, 115, 1-4. https://doi.org/10.1289/ehp.9149

Institut für Baubiologie + Ökologie. (2008). Building biology evaluation guidelines: For sleeping areas (K. Gustavs, Trans.). Retrieved from https://www.home-biology.com/images/emfsafetylimits/BuidlingBiologyLimits.pdf

Jeschke, R. (2011). California proposes strong privacy protections for smart meters. Electronic Frontier Foundation. Retrieved from https://www.eff.org/deeplinks/2011/05/ california-proposes-strong-privacy-protections

Lynch, J., \& Tien, L. (2010). Joint comments of the Center for Democracy \& Technology and the Electronic Frontier Foundation on proposed policies and findings pertaining to the smart grid: California Public Utilities Commission, Rulemaking 08-12-009. Retrieved from https://www. eff.org/files/cdteffjointcomment030910.pdf

Maret, K. (2011). Commentary on the California Council on Science and Technology Report "Health impacts of radio frequency from smart meters." Retrieved from http://sagereports.com/ smart-meter-rf/?p=368

Marino, A. A. (2010). Going somewhere: Truth about a life in science. Belcher: Cassandra.

Oreskes, N., \& Conway, E. M. (2010). Merchants of doubt: How a handful of scientists obscured the truth on issues from tobacco smoke to global warming. New York: Bloomsbury.

Orwell, G. (1949). 1984. London: Secker \& Warburg.

Rampton, S., \& Stauber, J. (2001). Trust us, we're experts! How industry manipulates science and gambles with your future. New York: Jeremy P. Tarcher/Putnam.

Senate Bill No. 17 (2009). California, USA.

Senate Bill No. 1476 (2010). California, USA.

Senate Bill No. 649 (2017). California, USA.

Singer, K. (n.d.). Medical implants: The effects of electromagnetic signals from wireless devices on medical implants and medical equipment. Retrieved from http://www.electronicsilentspring. com/primers/medical-implants/

Smart Energy Consumer Collaborative. (2020). Smart grid facts. Retrieved from https://smartenergycc.org/smartgrid101/

The Utility Reform Network. (2012). SM opt out costs should come profits, not rates. Retrieved from http://www.turn.org/press-release/sm-opt-out-costs-should-come-from-profits-not-rates/

Won, J., Ma, C. Y. T., Yau, D. K. Y., Rao, N. S. V. (2016). Privacy-assured aggregation protocol for smart metering: A proactive fault-tolerant approach. IEEE/ACM Transactions on Networking, 24, 1661-1674. https://doi.org/10.1109/TNET.2015.2425422 
Open Access This chapter is licensed under the terms of the Creative Commons Attribution 4.0 International License (http://creativecommons.org/licenses/by/4.0/), which permits use, sharing, adaptation, distribution and reproduction in any medium or format, as long as you give appropriate credit to the original author(s) and the source, provide a link to the Creative Commons license and indicate if changes were made.

The images or other third party material in this chapter are included in the chapter's Creative Commons license, unless indicated otherwise in a credit line to the material. If material is not included in the chapter's Creative Commons license and your intended use is not permitted by statutory regulation or exceeds the permitted use, you will need to obtain permission directly from the copyright holder. 